\title{
Petrología cerámica comparativa y análisis composicional de las pinturas por MEB-EDS de estilo Aguada Portezuelo ( $c a .600-900$ DC) en el valle de Catamarca (Noroeste Argentino)
}

Guillermo A. De La Fuente ${ }^{1}$, Néstor Kristcautzky ${ }^{2}$, Gustavo Toselli ${ }^{3}$ y Alberto Riveros ${ }^{4}$

\section{RESUMEN}

La cerámica de estilo Aguada Portezuelo del Noroeste Argentino posee un amplio repertorio de técnicas de acabado empleadas principalmente en los tratamientos de superficie y decoración. Por otro lado, los aspectos relacionados a su manufactura no han sido investigados todavía en profundidad. Las observaciones macroscópicas permiten establecer preliminarmente que estos fragmentos presentan una pasta de granulometría muy fina y compacta, destacándose la buena calidad del producto final obtenida a través del proceso de manufactura. En este trabajo se presentan los primeros resultados de un estudio de petrología cerámica y análisis composicionales de pinturas por Microscopia Electrónica de Barrido con Espectrometría de Energía Dispersiva (MEB-EDS) a un conjunto de fragmentos cerámicos asignados a este estilo.

Palabras claves: Aguada Portezuelo - petrología cerámica-MEB-EDS - arqueometría.

\begin{abstract}
The Aguada Portezuelo ceramic style from the Northwestern Argentine region presents a wide range of finishing techniques, mainly surface treatment and decoration. However, the aspects related to the manufacture of these ceramic vessels have not been fully investigated yet. The macroscopic observations conducted until now allow to preliminary establish that these ceramic sherds present a very fine-grained and compact ceramic fabric, mainly characterised by the good quality obtained in the final product. In this paper, we present the first results of a ceramic petrology study and compositional analyses by Scanning Electronic Microscopy with Energy Dispersive Spectrometry (SEM-EDS) carried out on a set of ceramic sherds assigned to this ceramic style.
\end{abstract}

Key words: Aguada Portezuelo - ceramic petrology - SEMEDS - archaeometry.

Recibido: noviembre 2004. Aceptado: julio 2005.

1 Escuela de Arqueología, Universidad Nacional de Catamarca, Campus Universitario $\mathrm{s} / \mathrm{n}^{\circ}$, Belgrano 300 (4700) Catamarca, ARGENTINA. Email: gfuente@ arqueologia.unca.edu.ar

\section{Introducción}

El estilo cerámico Aguada Portezuelo (ca. 600900 DC) del Noroeste Argentino presenta una gran variación y complejidad en las técnicas de manufactura concernientes a los tratamientos de superficie y la decoración aplicada a las vasijas (Kusch 1991, 1996-97; González 1998; Cremonte et al. 2003). Una de sus características más resaltantes es su marcada policromía, los motivos son elaborados en negativo y positivo y los colores utilizados en su decoración oscilan entre el "concho de vino" -o rojo púrpura-, rojizo, negro y amarillo, siendo este último color único en las cerámicas arqueológicas del Noroeste Argentino (González 1998). Algunas veces, los colores no han sido bien fijados por la cocción y aparecen como suaves y sin brillo presentando también pinturas pre y postcocción. Otro de sus aspectos técnicos decorativos muy poco estudiados es la existencia de pinturas negativas resistentes (González 1998).

Adicionalmente, un atributo concerniente a la manufactura de particular importancia es el tratamiento de superficie. La superficie interna de las vasijas es algunas veces de un color negro intenso pulido $\mathrm{y}$, en otros casos, presenta evidencias de la técnica de bruñido. Quizás, se trate de un proceso técnico relacionado con el ahumado de

2 Escuela de Arqueología, Universidad Nacional de Catamarca, Campus Universitario s/n $\mathrm{n}^{\circ}$, Belgrano 300 (4700) Catamarca, ARGENTINA. Email: nestorkris@yahoo.com

3 Laboratorio de Petrología, Facultad de Tecnología y Ciencias Aplicadas, Universidad Nacional de Catamarca, Belgrano 300 (4700) Catamarca, ARGENTINA. Email: gtoselli@tecno.unca.edu.ar

4 CONICET - Facultad de Matemática, Astronomía y Física, Universidad Nacional de Córdoba (5000) Córdoba, ARGENTINA. Email: beto@quechua.fis.uncor.edu 
la superficie interna de las vasijas y el posterior bruñido, aunque algunos autores han señalado que posiblemente se hayan utilizado elementos naturales con altos contenidos de grafito, por lo que también se suele denominar "grafitado" a este efecto visual (González 1998).

Los principales aspectos relacionados a los procesos de manufactura involucrados en el modelamiento y decoración de estas vasijas no han sido completamente estudiados a la fecha. Las observaciones macroscópicas y microscópicas (lupa binocular 20X-40X) realizadas hasta ahora permiten establecer preliminarmente, que esta cerámica presenta una pasta de granulometría muy fina y compacta, principalmente caracterizada por la presencia mineral de arenas cuarzosas redondeadas, biotita y muscovita como los principales constituyentes mineralógicos (González 1998; Cremonte et al. 2003).

En este trabajo se presentan los primeros resultados de un estudio comparativo de petrología cerámica llevado a cabo sobre un conjunto de fragmentos pertenecientes al estilo Aguada Portezuelo procedentes de varios sitios arqueológicos localizados en el valle de Catamarca (Kristcautzky y Togo 1996). Nuestro principal objetivo es discutir las características tecnológicas y el proceso de manufactura de este tipo cerámico y sus modalidades dentro del valle de Catamarca. Variables cualitativas como el tipo de matriz, porosidad, esfericidad y microfracturas, así como también variables cuantitativas -tipo de antiplástico identificado- son presentadas y discutidas. Se presentan los resultados preliminares de un estudio sobre las pinturas y engobes de estos fragmentos que está siendo llevado a cabo a través de la aplicación de la técnica analítica de Microscopia Electrónica de Barrido con Espectrometría de Energía Dispersiva (MEB-EDS). Finalmente, se discute la utilidad de la petrología cerámica para el estudio de la mineralogía específica de algunas clases de engobe aplicados a las superficies externas de las vasijas.

\section{Area geográfica}

El valle de Catamarca es un territorio geográfico muy ancho y extenso; tiene como sus principales límites la serranía de Ambato al oeste, con altitudes que llegan hasta los $4000 \mathrm{~m} . \mathrm{snm}$ y formaciones aluviales extendiéndose desde la base de la montaña hacia la parte central del valle. Hacia el este limita con la sierra de Ancasti, con una altitud máxima de $2000 \mathrm{~m} . \mathrm{snm}$ y una pendiente occidental muy aguda, siendo su ladera oriental mucho más suave. El límite norte está constituido por las sierras Gracianas, del Alto, y sierra de Fariñango, y el sur por las grandes planicies de la provincia de La Rioja, y la sierra Brava.

El fondo del valle está cruzado por los ríos del Valle y Paclín, corriendo con una dirección aproximada norte-sur, siguiendo los rasgos estructurales geológicos del valle.

Esta porción geográfica está caracterizada por un clima árido de sierra, y la región está fitogeográficamente clasificada como dominio neo-tropical chaqueño (Cabrera y Willink 1973).

\section{Antecedentes}

El estilo Aguada Portezuelo fue dado a conocer por primera vez a través de varios fragmentos de alfarería recolectados a comienzos del siglo $\mathrm{XX}$ por Lafone Quevedo en las dunas del puesto Las Garrochas, cerca de la ciudad de Andalgalá, Catamarca (Lafone Quevedo 1892: 52-56). Serrano (1958: 95-96, Fig. 44) le dio el nombre de estilo Huillapima Fondo Crema. Más tardíamente, en los sitios cercanos a la localidad homónima del Portezuelo, Petek y colaboradores (1972 Ms) llevaron a cabo excavaciones en varios asentamientos de esta localidad recuperando un importante número de fragmentos y piezas incompletas asignables al estilo. Barrionuevo (1971) también señaló la presencia de este estilo cerámico en la localidad de Nanahuasi, Departamento Ancasti, en los faldeos orientales de la sierra homónima. Haber (1992: 78-79 y 1996: 95), también en el valle de Catamarca, reportó nuevos sitios arqueológicos -principalmente de superficie- con algunos fragmentos Aguada Portezuelo, en las cercanías de la localidad de Miraflores (Departamento Capayán).

Kusch (1996-97), estudiando los diseños de la cerámica de este estilo ha identificado cuatro patrones estructurales de diseño: 1) patrón de franja continua; 2) patrón de triángulos y rombos; 3) patrón de escalonados (en franja de borde, de punto angular, y de centro); y 4) patrón de amplias franjas de borde; éste último asociado exclusivamente con las figuras humano-felínicas. En 
referencia a estos patrones, la autora señala la existencia de modalidades funcionales, pero relacionadas con un concepto de función entendido como una alternativa más comprensiva de una posible finalidad, probablemente pensando en un uso diferencial no determinado por la forma potencial de un contenedor, sino por el referente figurativo que explícitamente podría estar remitiendo a una función de tipo ceremonial, sugiriendo alguna forma institucionalizada de culto (Kusch 1996-97: 246; Kusch y Gordillo 1997).

Ultimamente, Kristcautzky y Togo (1996) a partir de una prospección arqueológica llevada a cabo en el valle de Catamarca, dieron a conocer varios sitios arqueológicos en los cuales encontraron fragmentos de estilo Aguada Portezuelo. En 1997, en la localidad de Choya (Departamento de Capayán), al suroeste del valle de Catamarca, fue detectado un sitio ceremonial, Choya-68, perteneciente a esta fase cultural, consistiendo en un montículo de base circular con una estructura troncocónica en su parte superior y un diámetro de aproximadamente $25 \mathrm{~m}$ (González 1998; Baldini et al. 2002; Cremonte et al. 2003).

El estudio de Cremonte y colaboradores (2003) se presenta como el antecedente directo del presente trabajo, ya que ellos analizaron 10 secciones delgadas procedentes del sitio Choya- 68 bajo microscopio polarizador, y un fragmento fue analizado composicionalmente por MEB-EDAX e IR -Espectroscopia Infrarroja. Sus resultados preliminares constituyen el primer avance en el estudio composicional a nivel mineralógico y químico para este estilo cerámico y serán discutidos y comparados con los nuestros en la sección Discusión y Conclusiones.

Este conjunto de investigaciones ha permitido conocer más en profundidad la distribución geográfica del estilo cerámico Aguada Portezuelo, el cual se presenta como muy bien definido dentro del valle de Catamarca, con manifestaciones materiales en el faldeo oriental de la sierra de Ancasti y el norte de la provincia de La Rioja. Su casi total ausencia al oeste de la sierra de Ambato resulta particularmente evidente, y los descubrimientos de alfarería de este estilo en las proximidades de la ciudad de Andalgalá son muy difíciles de interpretar debido principalmente a la ausencia de estudios de campo (González 1998).

\section{Materiales y métodos}

\section{Petrología cerámica}

Los análisis de petrología cerámica fueron llevados a cabo sobre un subconjunto de 10 fragmentos previamente seleccionados de una base de datos procesada en bajos aumentos por lupa binocular. ${ }^{5}$ Los fragmentos proceden de excavaciones estratigráficas en tres sitios arqueológicos localizados en el valle de Catamarca: El Portezuelo, La Carrera y Tiro Federal Sur, en la provincia de Catamarca (Figura 1). Los sitios arqueológicos mencionados están radiocarbónicamente datados en el Período Medio (ca. 600900 DC) y asignados a la Cultura de La Aguada del Noroeste Argentino (Gordillo 1996-97: 23; Kristcautzky y Togo 1996). La mayoría de los fragmentos pertenece a vasijas subglobulares y pucos recuperados de contextos funerarios, y corresponde a los siguientes tipos cerámicos: 1) Negro y Rojo sobre Blanco (Figura 2a), con interior negro pulido: Port. 002 (Figura 2b), Port. 003 y Port. 004; 2) Negro, Rojo y Marrón sobre Blanco con interior negro pulido Port. 001 (Figura 2c), TFS 750; 3) Negro y Rojo sobre Ante con interior ante: TFS 334 (Figura 2d), TFS 11, LCCI 001.

Los fragmentos fueron enviados para análisis petrológico (altas magnificaciones, 40X-100X), confeccionándose secciones delgadas de 0.030 $\mathrm{mm}(30 \mu)$ de espesor para su observación bajo el microscopio polarizador. De este modo, secciones delgadas verticales (Woods 1984-85: 105-107) fueron elaboradas y analizadas por los métodos convencionales aplicando para la fase cuantitativa de este estudio el método de "conteo de área total" (Figura 3) para las inclusiones minerales y los fragmentos de roca presentes en las secciones (Middletone et al. 1985; Freestone 1991; Mathew et al. 1991; Barraclough 1992). Este método constituye una medida genuina del número/distribución de frecuencias, determinando los números relativos de granos/inclusiones de un tamaño dado, para cada mineral o fragmento de roca, que yacen en un plano a través de la muestra. Para cada sección delgada fueron contadas en promedio 200 inclusiones (Middletone et al. 1985).

5 La elaboración de las secciones delgadas se realizó en el Laboratorio de Petrología, Facultad de Tecnología, Universidad Nacional de Catamarca, a cargo del Dr. Gustavo Toselli. 


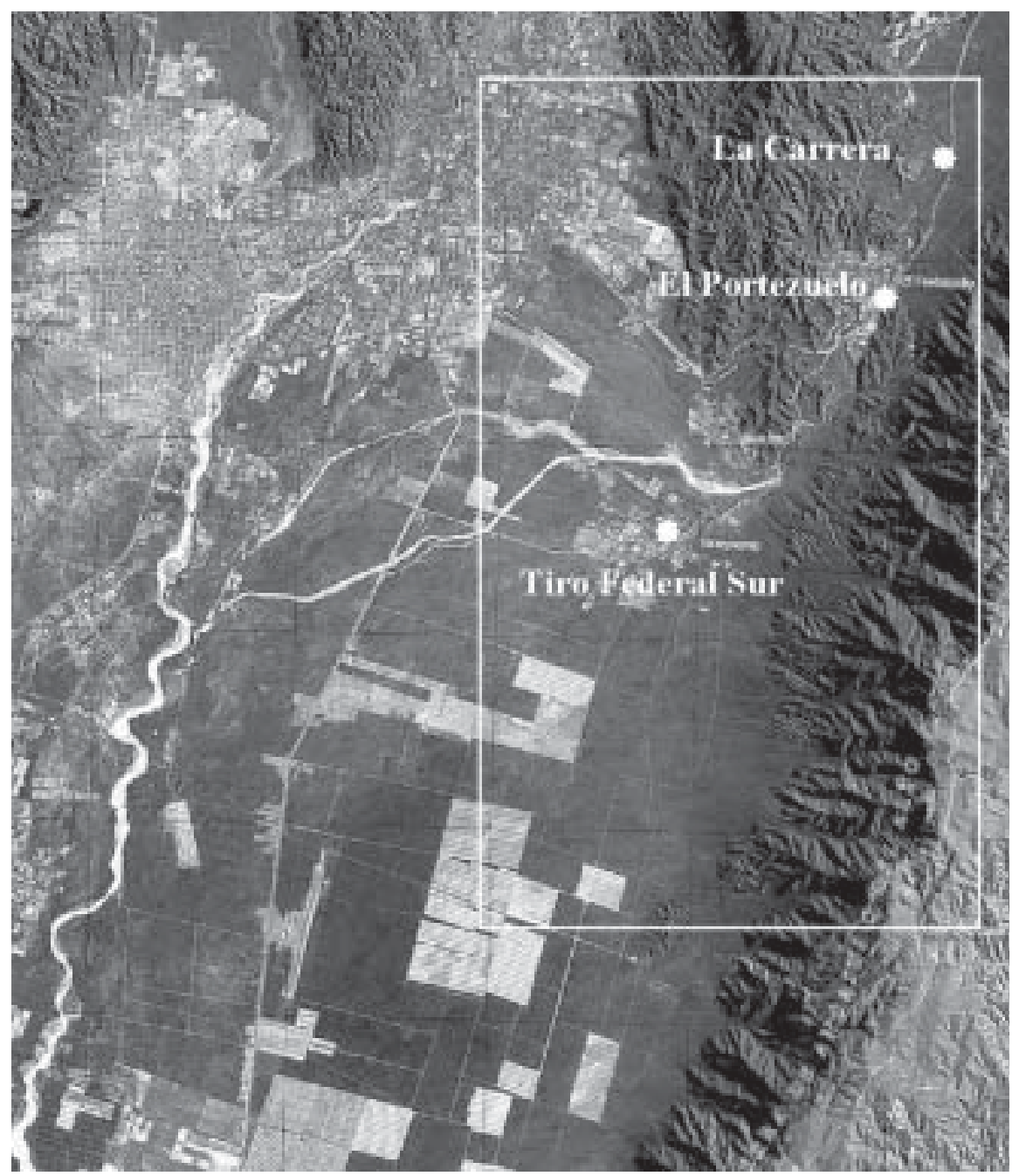

Figura 1. Valle de Catamarca: Sitios mencionados en el texto.

Los minerales y fragmentos de roca se identificaron en función de las características ópticas de los minerales bajo luz paralela (PPL) y luz cruzada polarizada (XPL):

1) Observaciones ortoscópicas

\begin{tabular}{|ll|}
\hline Luz Paralela (PPL) & Luz Cruzada $($ XPL) \\
\hline - color & - color de interferencia \\
- pleocroismo & - birrefringencia, $\gamma-\beta$ \\
- forma & - maclas \\
- hábito & - elongación \\
- clivaje & $-\mathrm{E}^{\circ}$, extinción \\
- n, índice de refracción & \\
- inclusiones & \\
- alteraciones & \\
\hline
\end{tabular}

2) Observaciones conoscópicas

- carácter óptico

- orientación óptica

$-2 \mathrm{v}$

- signo óptico

- dispersión

La escala de tamaño de los granos (escala $\varphi$ ) está basada en Hargrave y Smith (1928) y Ravines (1989) y da cuenta de los siguientes rangos: 1) -1 (2-4 mm); 2) 0 (1-2 mm); 3) 1 (0.5-1 mm); 4) 2 $(0.25-0.5 \mathrm{~mm})$; 5) 3-4 (0.063-0.25 mm); у 6) 5 (0.031-0.063 mm).

La identificación y el análisis de las secciones (observaciones ortoscópicas y conoscópicas) se 


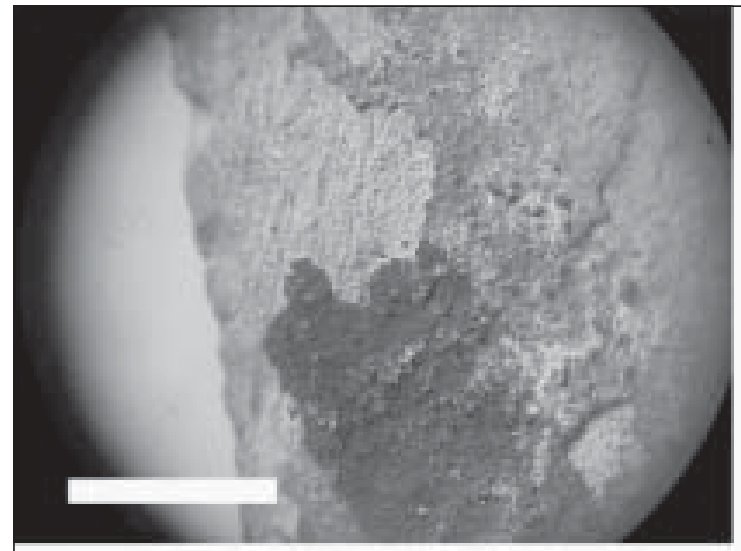

a

$\mathrm{c}$
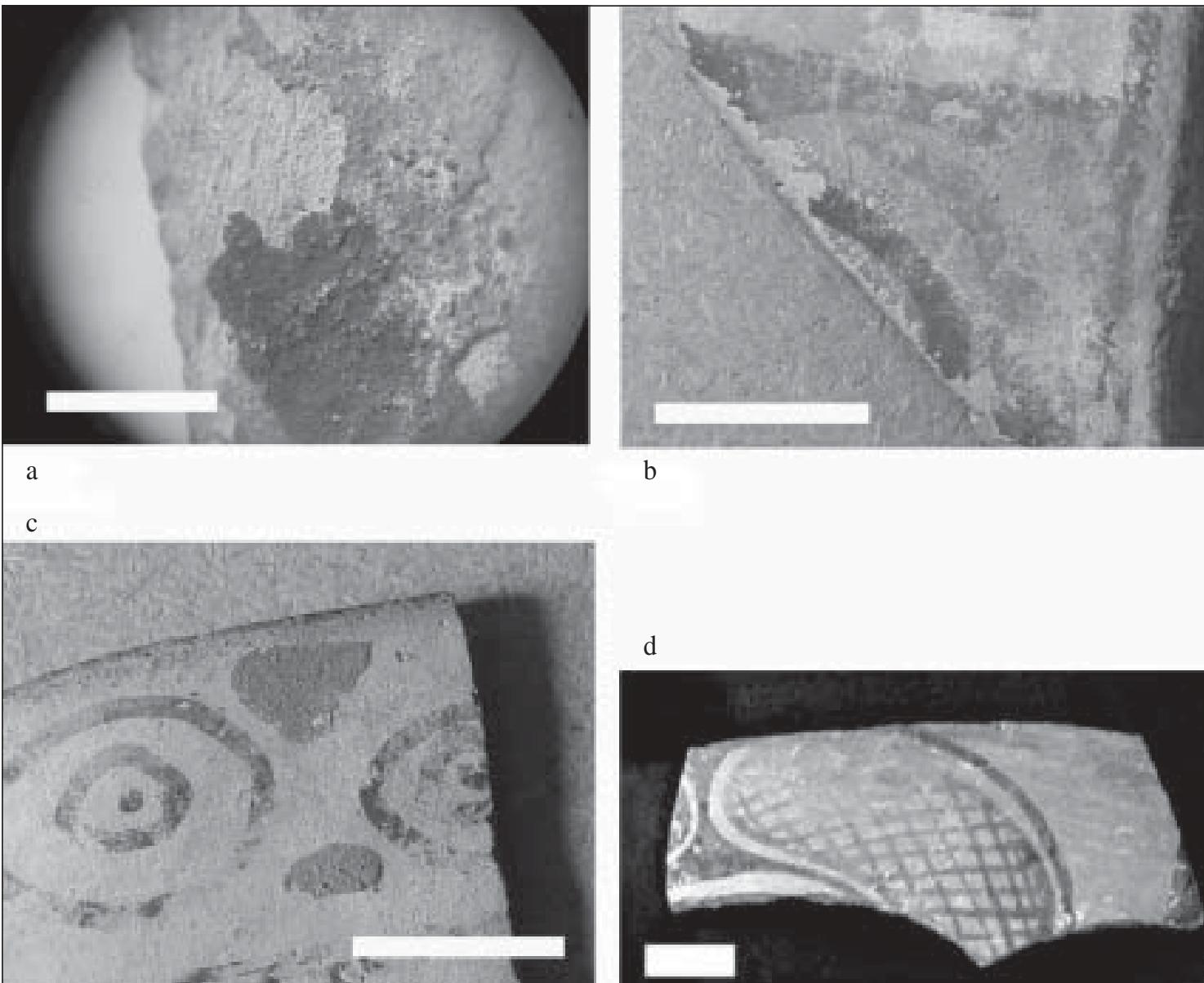

b

\section{$\mathrm{d}$}

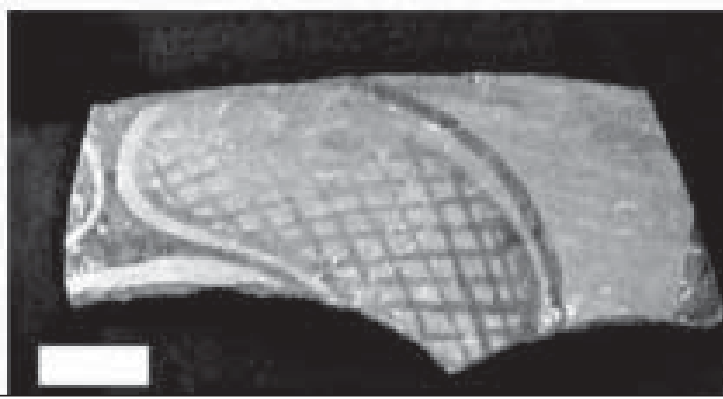

Figura 2. a) Pinturas rojo y negro postcocción sobre blanco, 20X. Escala: $1 \mathrm{~cm}$; b) Fragmento Port. 002. Rojo y Negro sobre Blanco. Escala: $1 \mathrm{~cm}$; c) Fragmento Port. 001. Rojo, Negro y Marrón sobre Blanco. Escala: $1 \mathrm{~cm}$; d) Fragmento TFS 334. Escala: $1 \mathrm{~cm}$.

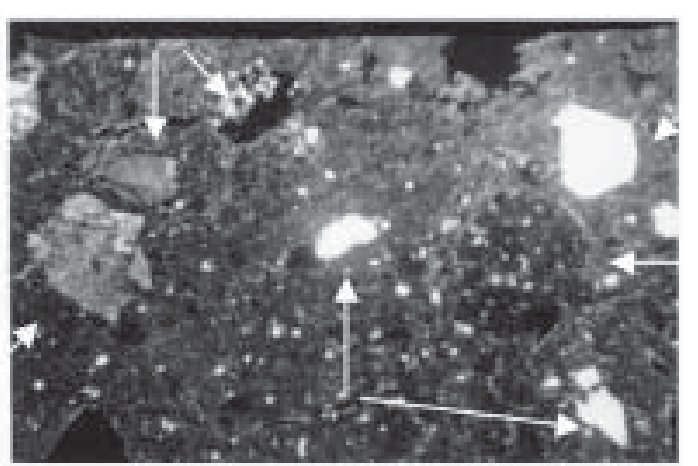

Figura 3. Método de conteo por "área total". 
realizaron utilizando microscopios polarizadores Enosa M-80-P2 y Meopta en magnificaciones 40X-100X, conjuntamente con un Microproyector de secciones delgadas marca Enosa 150, con una magnificación de 43X.

Las microfotografías fueron tomadas con un microscopio Karl Zeiss con un sistema de microfotografía acoplado al microscopio.

Microscopia Electrónica de

Barrido-Espectrometría de Energía

Dispersiva (MEB-EDS)

Los análisis se realizaron con un MEB Phillips 500 acoplado con un espectrómetro de energía dispersiva (EDS) EDAX PV 9760/86, Modelo P-500 - 139-2.5, en la Unidad de Materiales del Centro Atómico Constituyentes, Comisión Nacional de Energía Atómica, y en la Facultad de Química de la Universidad Nacional de San Luis.

Las muestras fueron metalizadas utilizando $\mathrm{Au}$ para volverlas conductivas y analizarlas bajo el MEB. Se analizaron superficies de cerámicas que contenían pigmentos de colores: 1) negro; 2) blanco; 3) rojo; 4) marrón; y 5) superficies internas pulidas de color negro intenso denominadas en la literatura como "grafitadas". Algunas secciones transversales fueron pulidas con los métodos convencionales petrológicos y analizadas transversalmente.

\section{Resultados}

Análisis petrológicos de las pastas cerámicas

Los 10 fragmentos analizados presentan una composición mineralógica muy homogénea caracteri- zada por pastas muy finas compactas compuestas principalmente por materiales félsicos como inclusiones de cuarzo monocristalino, biotitas y, en menor cantidad, inclusiones de muscovitas. En cantidades menores se observaron inclusiones de fragmentos de rocas ígneas plutónicas (básicamente granitos y granitoides) en tamaño medio, calcita primaria y secundaria y fragmentos de rocas arcillosas; algunas veces combinados con materiales máficos como anfíboles (hornblenda parda) y piroxenos/clinopiroxenos de granulometría fina. El cuarzo monocristalino es en muchos casos típico de las arenas cuarzosas redondeadas características de ambientes fluviales. El cuarzo policristalino también está presente en algunos fragmentos. Todos los fragmentos presentan una matriz micácea de granulometría fina y ultra fina, caracterizada principalmente por biotita y en menor extensión por muscovita. Adicionalmente, en la mayoría de los fragmentos analizados se observaron inclusiones opacas con una distribución heterogénea en las secciones delgadas.

La Tabla 1 nos da los detalles de la distribución del antiplástico para los fragmentos analizados. Los valores están expresados en porcentajes (\%) relativos de cada antiplástico. A partir de esta tabla puede observarse que el $100 \%$ de los fragmentos presenta granos de cuarzo redondeados $(\mathrm{Q})$ como el principal antiplástico, combinado principalmente con biotita (B) y muscovita (M). Otras inclusiones presentes en bajas proporciones son los feldespatos plagioclasa (FPL), fragmentos de rocas ígneas plutónicas -granito-(IRF), calcita (Ca) y fragmentos de rocas arcillosas (ARF) (Figuras 4a, b, c y d). Entre los feldespatos plagioclasa identificados, algunos de ellos presentan evidencias de alteraciones a sericita.

\begin{tabular}{|c|c|c|c|c|c|c|c|c|c|c|}
\hline Código de referencia & $\mathbf{Q}$ & Pl. Q & FPI & B & $\mathbf{M}$ & IRF & $\mathrm{Ca}$ & ARF & Amph & Px \\
\hline Port. 001 & 54 & 3.7 & & 23 & 11 & 5.2 & & & & 3 \\
\hline Port. 002 & 50 & 4.6 & & 23.2 & 15.9 & 3.3 & $3.3(\mathrm{~s})$ & & & \\
\hline Port. 003 & 44 & & 7 & 25 & 19 & 3 & $2.5(\mathrm{p})$ & & & \\
\hline Port. 004 & 44.3 & & 5 & 17 & 21 & 8 & & 4.5 & & \\
\hline LCCI 001 & 50 & 2.5 & 6.6 & 24.9 & 6.6 & 8.6 & & & & \\
\hline TFS 750 & 39 & & 7.7 & 24.5 & 12.5 & 7.8 & $6(\mathrm{~s})$ & 2.4 & & \\
\hline TFS 548 & 47.5 & & & 27.8 & 19 & 5.5 & & & & \\
\hline TFS 358 & 55 & & & & 18.5 & 9.6 & $9(\mathrm{~s})$ & 7.8 & & \\
\hline TFS 11 & 37.6 & & 2 & 24 & 18.3 & 8.4 & 3 & 5.4 & 1.4 & \\
\hline TFS 334 & 52 & & 5.7 & 36.3 & & 6.4 & & & & \\
\hline
\end{tabular}

Tabla 1. Distribución del antiplástico en los fragmentos analizados. Referencias: $\mathrm{Q}=$ cuarzo; $\mathrm{Pl}$. Q=cuarzo policristalino; $\mathrm{FPl}=\mathrm{feldespato}$ plagioclasa; $\mathrm{B}=$ biotita; $\mathrm{M}=$ moscovita; $\mathrm{IRF}=$ fragmento de roca ígnea (granito); $\mathrm{Ca}=$ calcita, (p) primaria, (s) secundaria; $\mathrm{ARF}=$ fragmento de roca arcillosa; Amph=anfíbol; Px=piroxeno. 


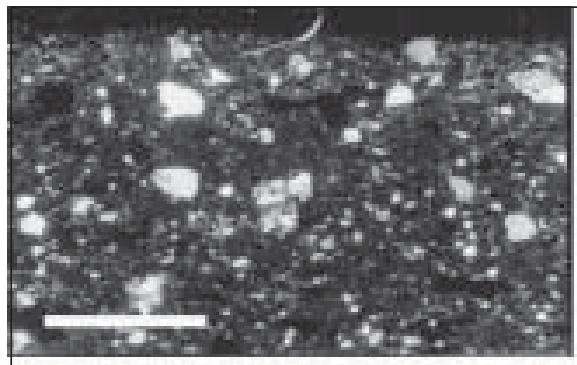

a

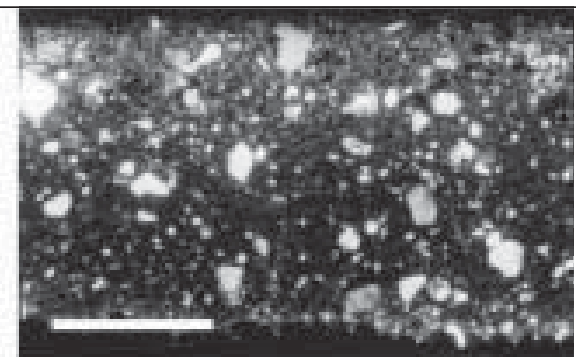

b

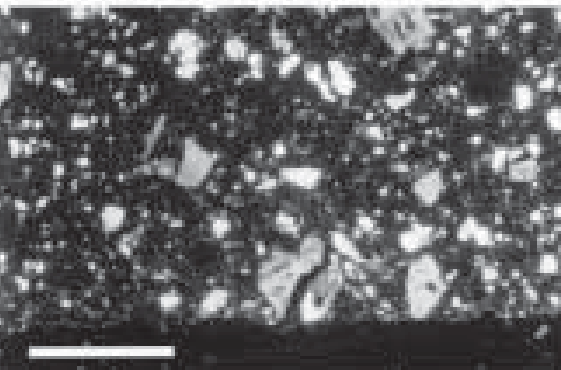

c

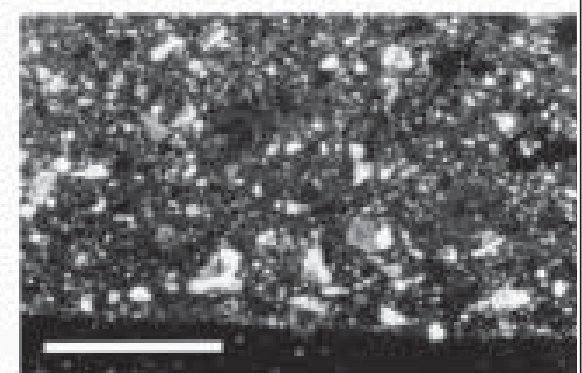

d
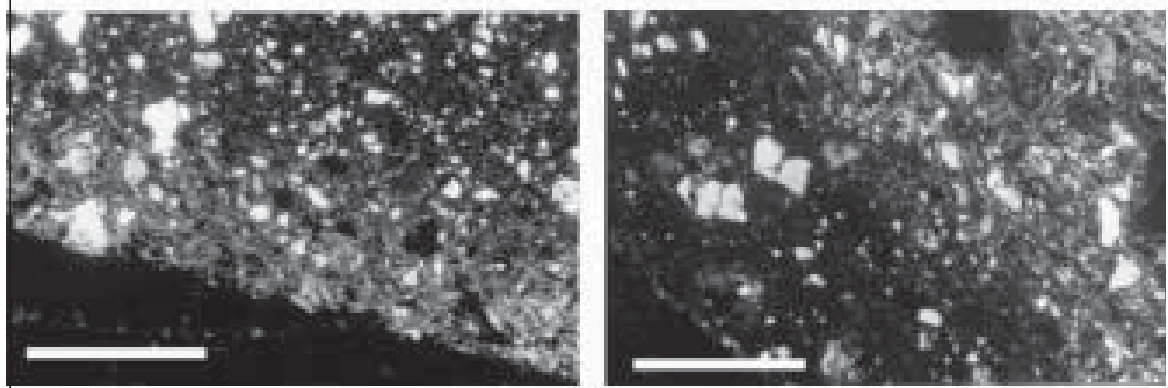

e

$\mathrm{f}$

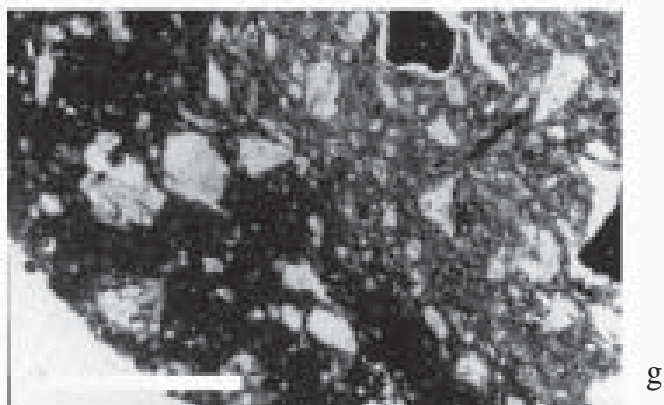

Figura 4. Microfotografías de fragmentos: a) Port. 001 (XPL). Cuarzo redondeado, biotita, muscovita, cuarzo policristalino y fragmentos de rocas ígneas. Escala: $2.5 \mathrm{~mm}$; b) Port. 004 (XPL). Matriz, cuarzo, biotita, muscovita y feldespato plagioclasa. Obsérvese las inclusiones de cuarzo redondeado. Escala: $2.5 \mathrm{~mm}$; c) LCCI 001 (XPL). Matriz, cuarzo, frag. Roca ígnea, biotita, muscovita y feldespato alterado a sericita. Escala: $2.5 \mathrm{~mm}$; d) TFS 750 (XPL). Matriz, cuarzo, cuarzo policristalino, fragmento roca ígnea, biotita y muscovita. Escala: $2.5 \mathrm{~mm}$; e) LCCI 001 (XPL). Matriz y engobe mostrando la mineralogía diferencial del resto de la pasta. Escala: $2.5 \mathrm{~mm}$; f) Microfotografía del fragmento Port. 002 (XPL). Vista del límite entre el engobe y la matriz. Escala: 1.2 mm; g) Microfotografía del fragmento Port. 002 (PPL). 
Para la muestra completa se realizaron las siguientes observaciones:

a) Orientación de las inclusiones: Ocho fragmentos muestran una orientación preferencial y dos fragmentos no presentan ninguna orientación.

b) Proporción total de las inclusiones: Ocho fragmentos poseen $20 \%$ de inclusiones por volumen, un fragmento tiene $15 \%$, y un fragmento posee el $10 \%$.

c) Distribución: Seis fragmentos poseen una distribución equilibrada, tres fragmentos tienen una distribución buena, y un fragmento distribución muy buena.

d) Anisotropía: Todos los fragmentos presentan características anisotrópicas -ópticamente activosen la matriz.

e) Composición al fondo de pasta: Ocho fragmentos poseen contenido micáceo (biotita y muscovita) y dos fragmentos tienen contenido micáceo muy fino (solamente biotita).

f) El principal rango de tamaño registrado para las inclusiones de cuarzo monocristalino fue fino (3-4 -0.063-0.25mm-) en la escala $\varphi$ de tamaños de grano.
El Gráfico 1 muestra la distribución de las diferentes inclusiones minerales y fragmentos de roca (granito) por rangos de tamaño para el fragmento Port. 002. Se observa que para la variable $\mathrm{Q}$ el rango de tamaño más representado es el 3-4 (0.063-0.031 mm), mientras que el rango de tamaño 2 (0.25-0.50 mm) está muy bien representado para todos los minerales y fragmentos de roca identificados en la muestra. El Q monocristalino en el rango de tamaño 3-4 presenta cristales subangulosos, automorfos y algunos de ellos están fracturados. La B y M presentan una distribución semejante con una mayor representación de estas inclusiones dentro del rango 3-4 (0.063-0.031 $\mathrm{mm})$. Si bien en este fragmento no se observa una distribución bimodal en sentido estricto para la variable $\mathrm{Q}$, puede establecerse que existe una fracción deliberadamente agregada de estas inclusiones en los rangos de tamaño 2 (0.25-0.50 mm), 1 (0.5-1mm) y 0 (1-2 mm), lo cual también está reflejado en una menor esfericidad de las inclusiones registrada para estos rangos de tamaño. Las inclusiones de B y $M$ presentan formas de laminillas subredondeadas y una distribución homogénea en la sección delgada. El Q policristalino y los fragmentos de rocas ígneas (granito) presentan formas angulosas y una distribución heterogénea en la pasta; la calcita en fase secundaria presenta formas subangulosas y está principalmente caracterizada por la agregación de cris-

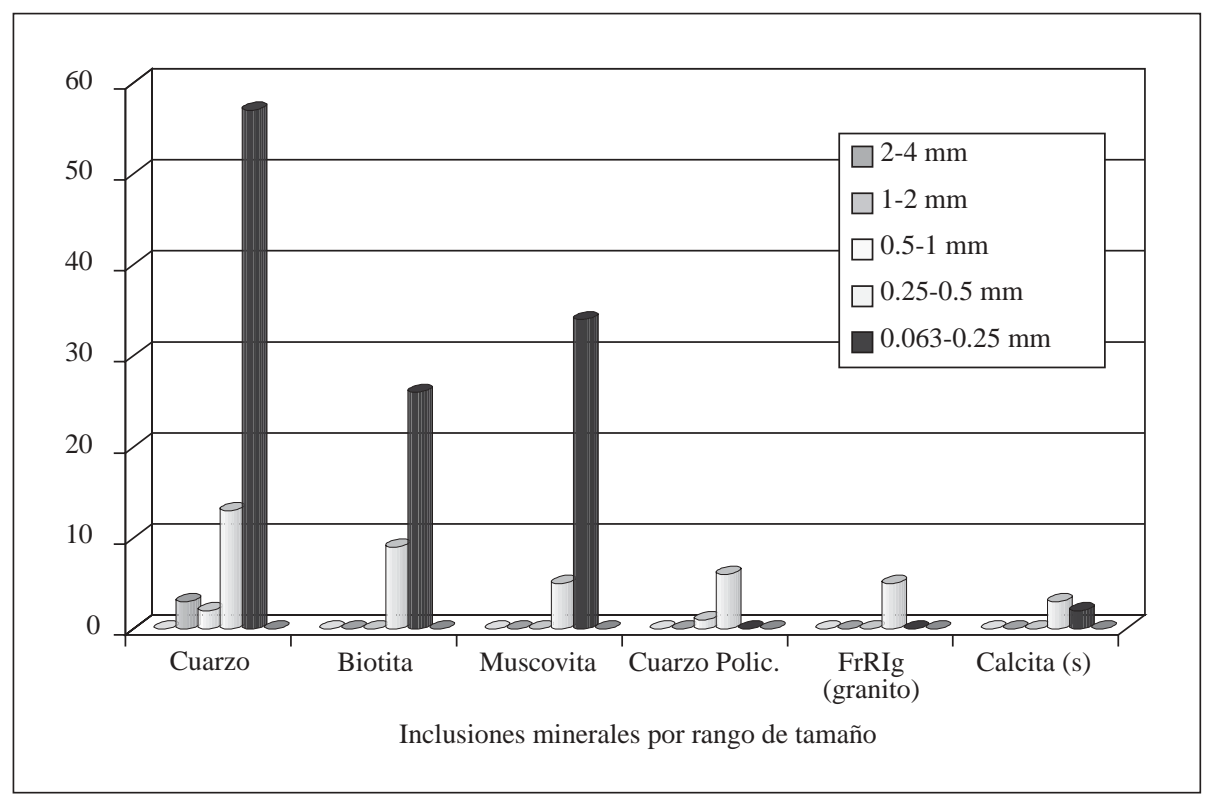

Gráfico 1. Distribución de inclusiones minerales y fragmentos de roca en fragmento PORT. 002. 
tales criptocristalinos en las cavidades y una distribución heterogénea en la pasta.

Las cavidades presentes en esta sección poseen una forma elongada y subrectangular parcialmente orientadas a lo largo del eje longitudinal de la sección delgada. Las mismas oscilan en tamaño entre $0.1 \mathrm{~mm}$ y $0.6 \mathrm{~mm}$.

En general, una buena correlación fue observada entre los datos obtenidos por análisis petrológico y aquellos de lupa binocular. La mayoría de los fragmentos analizados presentan diferentes tratamientos de superficie como parte de su decoración: a) la superficie externa presenta un engobe de color blanco precocción (10YR 8/1) con pinturas postcocción en color rojo $(2.5 \mathrm{YR} 4 / 2)$, negro (10YR 3/1) y marrón $(7.5 \text { YR 5/4 })^{6}$; b) algunos de los fragmentos muestran una superficie externa pulida de color marrón (7.5YR 6/4), con pinturas rojas $(2.5 \mathrm{YR} 4 / 2)$ y negras (7.5YR 4/1) postcocción ${ }^{7}$; c) la superficie interna generalmente presenta un color negro intenso pulido $(4 / \mathrm{N}){ }^{8}$ La Tabla 2 presenta información sobre las principales características técnicas (tipo de pieza, forma fragmento, colores de las pinturas en las superficies interna y externa, color núcleo, textura, cocción, tratamiento de superficie y técnica de decoración) de los fragmentos estudiados con microscopia binocular a 20X. De la Tabla 2 puede desprenderse que los tres tipos cerámicos (ver Notas 6 y 7) presentan pinturas postcocción tanto en la superficie externa como interna, a veces aplicada sobre el engobe blanco precocción sobre la superficie externa. Este engobe blanco precocción la mayoría de las veces presenta una exfoliación y un descascaramiento produciéndose su posterior desprendimiento del cuerpo de la vasija, lo que afecta la conservación total de este tipo de piezas. Este fenómeno se origina en las diferentes tasas de contracción que presenta tanto el cuerpo de la vasija como la solución coloidal (minerales arcillosos) aplicada sobre ésta. Dado que generalmente el engobe en una pieza se aplica cuando todavía está en "estado cuero", es de-

6 1) Tipo cerámico Negro y Rojo sobre Blanco, con interior negro pulido, y 2) tipo Negro, Rojo y Marrón sobre Blanco con interior negro pulido.

7 Tipo cerámico Negro y Rojo sobre Ante con interior ante.

8 Los colores fueron registrados con la Munsell Color Chart (1994). Edición Revisada. Kollmorgoren Instruments Co., Nueva York. cir, que posee grandes cantidades de humedad dentro de sus poros o cavidades; cuando la vasija se deja secar a temperatura ambiente la tasa total de contracción por pérdida de agua de su cuerpo es mucho mayor que la del engobe aplicado sobre su superficie - externa o interna-, proceso que es acelerado durante las primeras etapas de la cocción (hasta alcanzar los $100^{\circ} \mathrm{C}$ ). Ello producirá que el engobe se microfragmente (produciéndose un fenómeno que se denomina "crazing" [Simon 1996: 2 y 13] también utilizado para explicar el deterioro de los vidriados en cerámicas), no penetre eficazmente dentro de los poros de la superficie cerámica y finalmente, con el tiempo, se desprenda y se deteriore.

Algunos fragmentos tales como LCCI 001 y Port. 001 presentaron un engobe marrón (10YR 5/3) caracterizado principalmente por la presencia de grandes cantidades de inclusiones de biotita preferencialmente orientadas y con una mineralogía diferencial del resto de las pastas (Figura 4e y Tabla 2). Estos engobes fueron aplicados sobre una vasija con una pasta reducida $(5 / \mathrm{N})$ y luego fijadas en una segunda cocción oxidante de baja temperatura y corta duración (Figuras 4f, 4g y 5a), y su espesor oscila entre 0.5-0.6 mm, observándose una continuidad uniforme a través de la sección transversal investigada.

Adicionalmente, las observaciones realizadas bajo microscopio polarizador de las secciones delgadas verticales permitieron determinar que la totalidad de los fragmentos analizados pertenecen a vasijas cuya principal técnica de manufactura primaria es el levantamiento por rodetes de aproximadamente $1-1.5 \mathrm{~cm}$ de ancho. Se pudo observar que la mayoría de las secciones delgadas analizadas presentaron evidencias de la unión de 1 o 2 rodetes, con una alineación preferencial de las inclusiones minerales equiaxiales (biotitas y muscovitas) acorde con este tipo de técnica de manufactura primaria (Woods 1984-85: 105-107; Carr 1990: 17) (Figuras 6 y 7).

Análisis composicionales de pinturas por MEB

El fragmento TFS 334, procedente del sitio arqueológico Tiro Federal Sur, fue seleccionado para realizar un análisis composicional químico por MEB con microsonda EDS a los efectos de estudiar las pinturas, los pigmentos y la constitución 


\begin{tabular}{|c|c|c|c|c|c|c|c|}
\hline 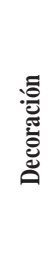 & 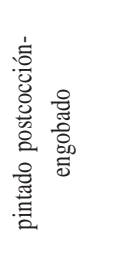 & 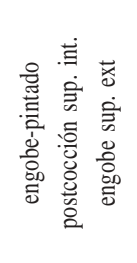 & 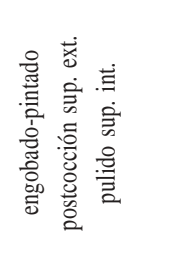 & 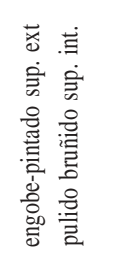 & 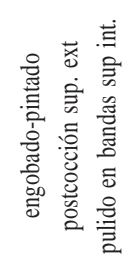 & 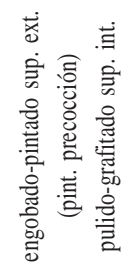 & 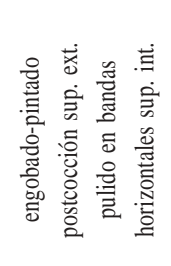 \\
\hline 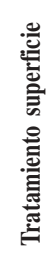 & 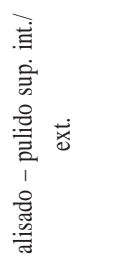 & 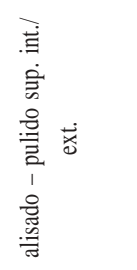 & 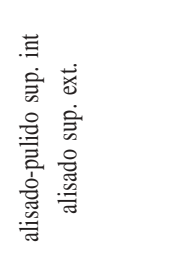 & 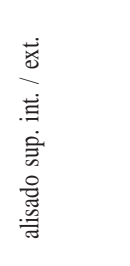 & 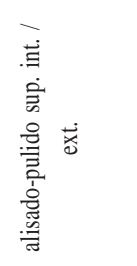 & 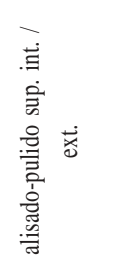 & 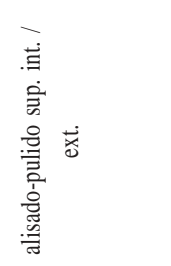 \\
\hline : & 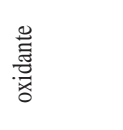 & 莺 & 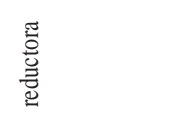 & 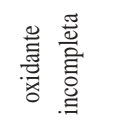 & 营 & 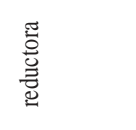 & 芉 \\
\hline 莺 & 葛 & 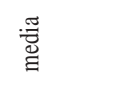 & 芭 & 䍛 & 怱 & 芭 & 芭 \\
\hline 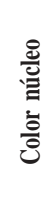 & 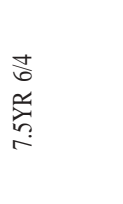 & \begin{tabular}{l} 
索 \\
\multirow{2}{*}{} \\
in
\end{tabular} & zin & 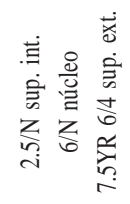 & 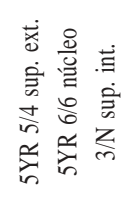 & 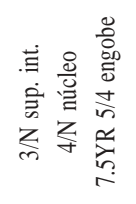 & 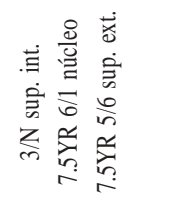 \\
\hline 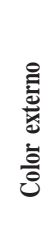 & 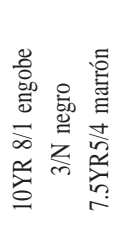 & 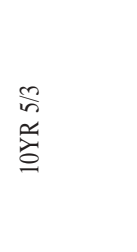 & 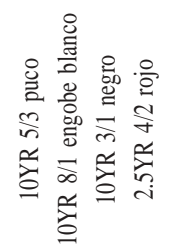 & 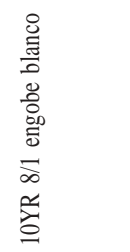 & 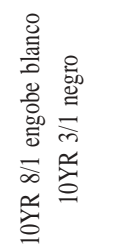 & 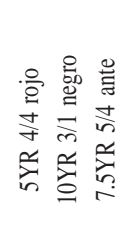 & 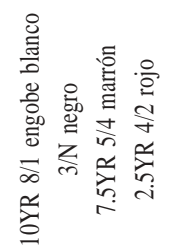 \\
\hline 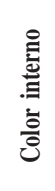 & 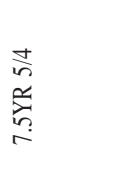 & 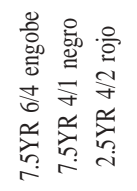 & z & 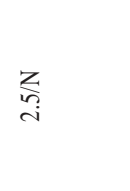 & $z_{m}$ & 㘶 & z \\
\hline 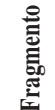 & 营 & 莺 & 嵪 & 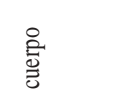 & 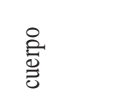 & 啇 & 产 \\
\hline 莺 & $\begin{array}{l}\frac{5}{0} \\
\frac{\bar{z}}{b 0} \\
\frac{\Xi}{0}\end{array}$ & 气 & $\stackrel{\varpi}{\sigma}$ & $\stackrel{\varpi}{\bar{\sigma}}$ & $\stackrel{\pi}{\bar{\sigma}}$ & 气 & $\stackrel{\Xi}{0}$ \\
\hline & 离 & 己. & 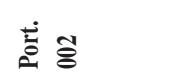 & 离 & 䓌 & 色 疍 & 兽 \\
\hline
\end{tabular}




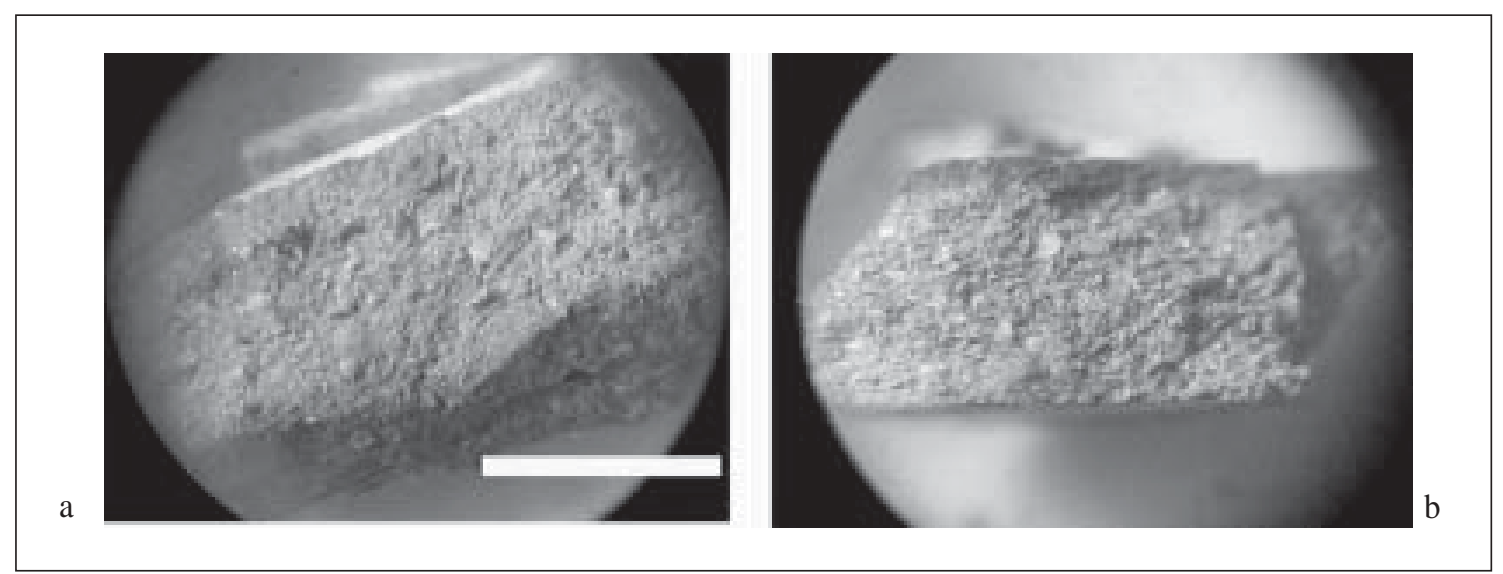

Figura 5. Vista de engobes: a) Engobe del fragmento Port. 001. Obsérvese el engobe color marrón sobre la superficie externa, 20X. Escala: $1 \mathrm{~cm}$; b) Vista transversal del fragmento TFS 334, 20X. Engobe superficie externa, con cocción oxidante. Escala: $1 \mathrm{~cm}$.

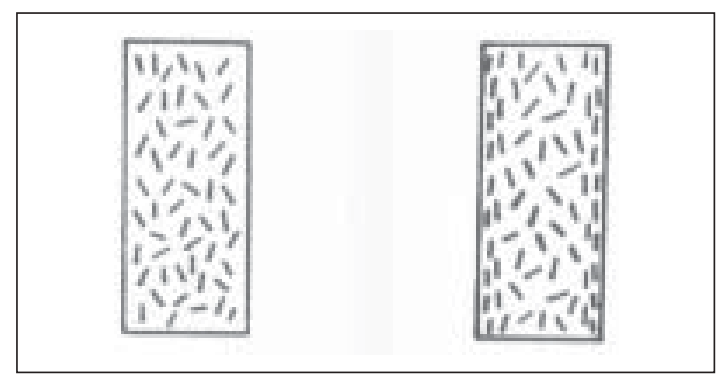

Figura 6. Alineación de las inclusiones minerales equiaxiales (B y M) en secciones delgadas verticales. Técnica de manufactura primaria por rodetes. En la figura de la derecha se puede observar efecto del pulido sobre la alineación de las inclusiones.

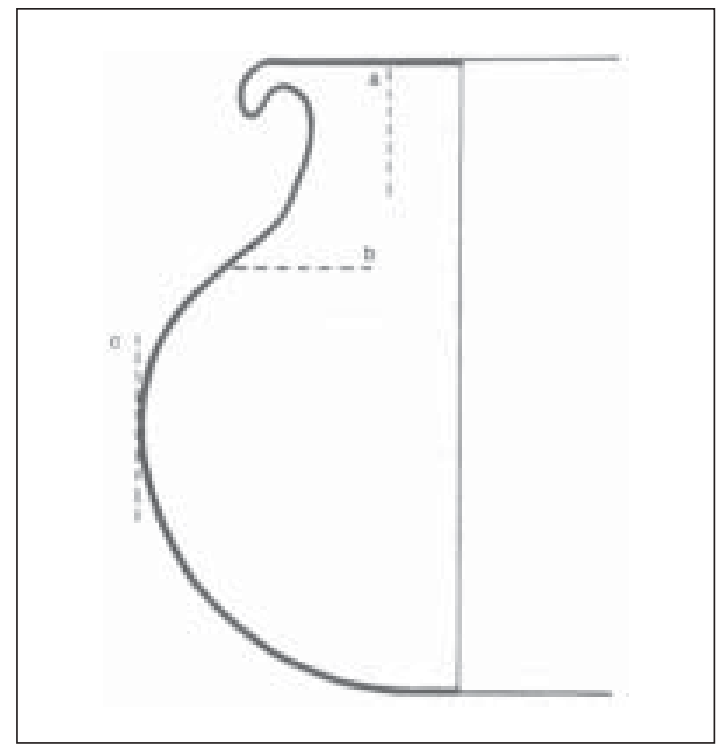

Figura 7. Vista de las diferentes secciones delgadas en una vasija cerámica: a) verticales; b) horizontales; y c) tangenciales. Dibujo adaptado de Woods (1984-85: 101). de su engobe (Figuras 2d y 5b) (De La Fuente $e t$ al. 2004). Para los aspectos analíticos, se siguieron los procedimientos descritos en la sección Materiales y Métodos.

El fragmento pertenece a la zona media del cuerpo de un puco Aguada Portezuelo del tipo Negro (10YR 3/1) y Rojo (5YR 4/4) sobre Ante (7.5YR 5/4) en su superficie externa y Negro Pulido (4/ N) -grafitado- en su superficie interna. El corte transversal mostrado en la Figura $5 \mathrm{~b}$ presenta los siguientes colores: $3 / \mathrm{N}$ superficie interna, $4 / \mathrm{N}$ sector medio del corte y 7.5YR 5/4 engobe superficie externa. Su pasta está constituida por inclusiones de cuarzo y biotita de granulometría media y fina, respectivamente, complementada por fragmentos de roca ígnea -plutónicas- con texturas graníticas de granulometría media distribuidas heterogéneamente en la sección delgada (ver Anexo 1 para la descripción petrológica). Presenta un engobe externo, con cocción oxidante, caracterizado por la presencia de gran cantidad de inclusiones de biotita orientadas a lo largo del eje longitudinal de la sección, de un espesor aproximadamente de $0.35 \mathrm{~mm}$ (ver Anexo 1).

Se analizaron dos muestras de cada una de las pinturas que conforman los motivos decorativos: 1) color rojo: óvalos del motivo felínico; 2) color negro: cuerpo del felino; 3) engobe marrón: superficie externa; 4) color negro: superficie interna; y 5) una sección transversal del fragmento pulido: interfaz entre el engobe y la matriz.

La Tabla 3 muestra los porcentajes relativos de las concentraciones de los elementos quí- 
GUILLERMO A. DE LA FUENTE, NESTOR KRISTCAUTZKY, GUSTAVO TOSELLI, ALBERTO RIVEROS

\begin{tabular}{|lcccc|}
\hline \% elemento & Pintura negra & Pintura roja & Engobe marrón & Sup. negra int \\
\hline $\mathrm{Fe}$ & 71.76 & 56.23 & 27.72 & 17.63 \\
$\mathrm{Mn}$ & 14.37 & 2.37 & - & - \\
$\mathrm{Ca}$ & 7.12 & - & 10.59 & - \\
$\mathrm{K}$ & - & 9.18 & 14.32 & 11.86 \\
$\mathrm{Al}$ & 2.18 & 15.97 & 13.24 & 15.54 \\
$\mathrm{Si}$ & 4.8 & 25.04 & 27.94 \\
\hline
\end{tabular}

Tabla 3. Concentraciones relativas de elementos químicos para las diferentes pinturas analizadas por MEB-EDS.

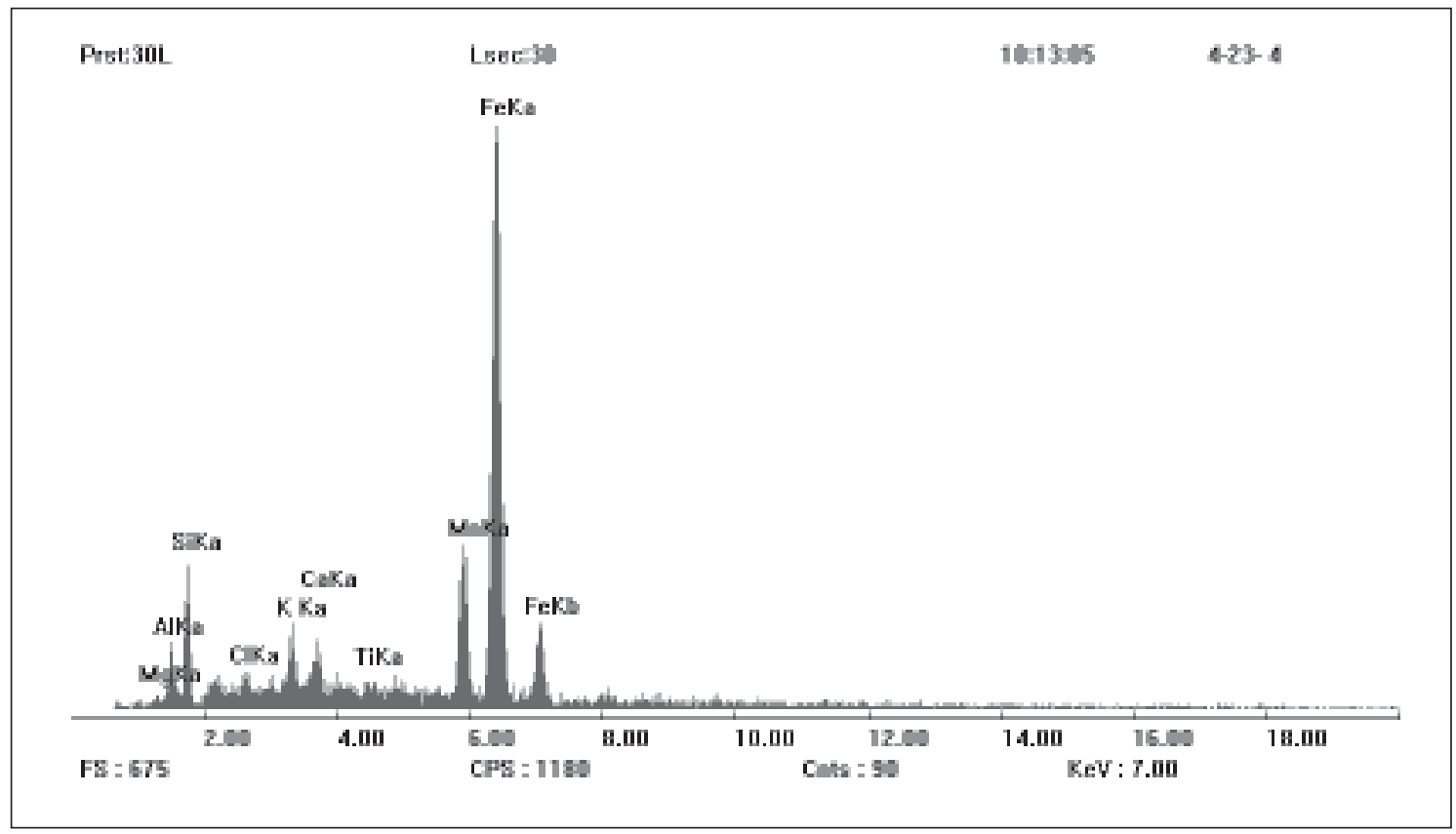

Gráfico 2. Fragmento TFS 334. Espectro 1.

micos determinados por EDS en las pinturas analizadas:

- Pigmento negro: Caracterizado por altas concentraciones de hierro (Fe: $72 \%$ ) y en segundo lugar por concentraciones de manganeso $(\mathrm{Mn}$ : $14 \%)+$ cantidades menores de calcio $(\mathrm{Ca}: 7 \%)+$ mineral arcilloso (aluminosilicato: $7 \%$ ) como vehículo del pigmento (Gráfico 2, espectro 1 y Figura 8a).

- Pigmento rojo: Caracterizado por altas concentraciones de hierro (Fe: 56\%) + cantidades menores de potasio $(\mathrm{K}: 9 \%)+$ mineral arcilloso (aluminosilicato: $25 \%$ ) como vehículo del pigmento + trazas de manganeso (Mn: 2\%) (Gráfico 3, espectro 2 y Figura 8b).
Engobe marrón: Mineral arcilloso (aluminosilicato: $38 \%)+$ concentración moderada de hierro (Fe: $28 \%)+$ potasio $(\mathrm{K}: 14 \%)+$ calcio $(\mathrm{Ca}: 11 \%)$ (Gráfico 4, espectro 3).

Superficie interna Negra pulida: Mineral arcilloso (aluminosilicato: $44 \%)+$ hierro $(\mathrm{Fe}: 18 \%)+$ potasio (K: 12\%) (Gráfico 5, espectro 4).

Estas pinturas son pigmentos mates, no vidriados, y deben adherirse a la superficie de la vasija y retener el color después del proceso de cocción.

Los pigmentos son incorporados a un coloide (alumino-silicato-mineral arcilloso) el cual forma el vehículo del pigmento y que debe reunir condiciones específicas para lograr su absorción en la superficie de la pasta cerámica. 


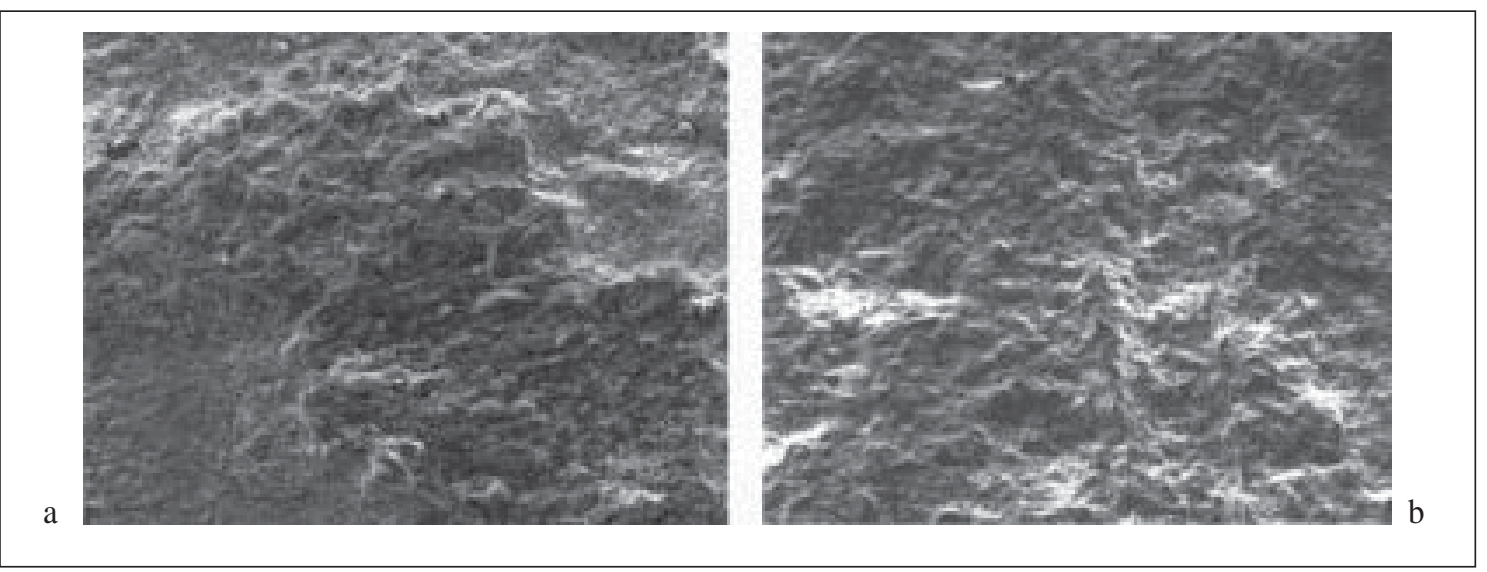

Figura 8. Microfotografía del fragmento TFS 334 por MEB, electrones secundarios: a) Pigmento negro, 200X; b) Pigmento rojo, 200X.

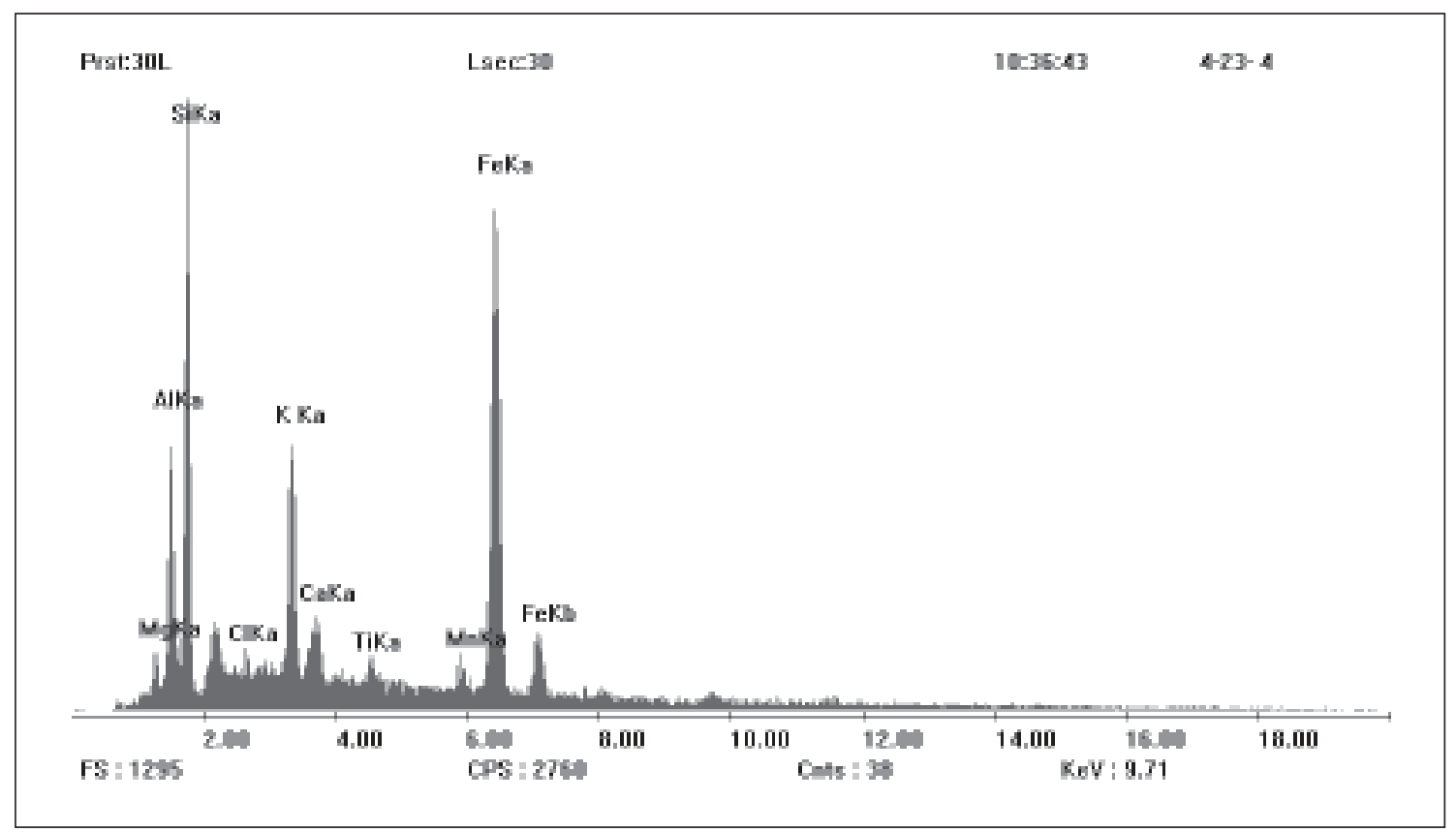

Gráfico 3. Frag. TFS 334. Espectro 2.

Los microanálisis por MEB-EDS realizados a distintas muestras de pigmento negro confirman que el origen del mismo es mineral, siendo la fuente de este pigmento probablemente el mineral hematita $\left(\alpha-\mathrm{Fe}_{2} \mathrm{O}_{3}\right)^{9}$, el cual da colores negros si se lo uti-

9 Actualmente, están siendo realizados análisis de estas pinturas por Difracción de Rayos X y Espectroscopia Infrarroja a los efectos de determinar analíticamente las fases minerales involucradas (hematita, ilmenita, pirolusita, psilomelano, dolomita, etc.) (Wilson 1987: 26-99). liza en condiciones naturales sin oxidación o bajo condiciones reductoras de cocción. Las concentraciones menores de manganeso $(\mathrm{Mn})$ en esta fase analizada pueden deberse a una combinación de diferentes minerales como la pirolusita $\left(\mathrm{Mn}^{+4} \mathrm{O}_{2}\right)$ o el psilomelano $\left(\mathrm{BaMn}^{+2}+\mathrm{Mn}_{8} \mathrm{O}_{16}(\mathrm{OH})_{4}\right)^{10}$ con hematita para obtener el color negro.

10 El psilomelano no presenta una fórmula fija dado que presenta combinaciones variadas de elementos químicos, por lo que la fórmula presentada aquí es tentativa. 


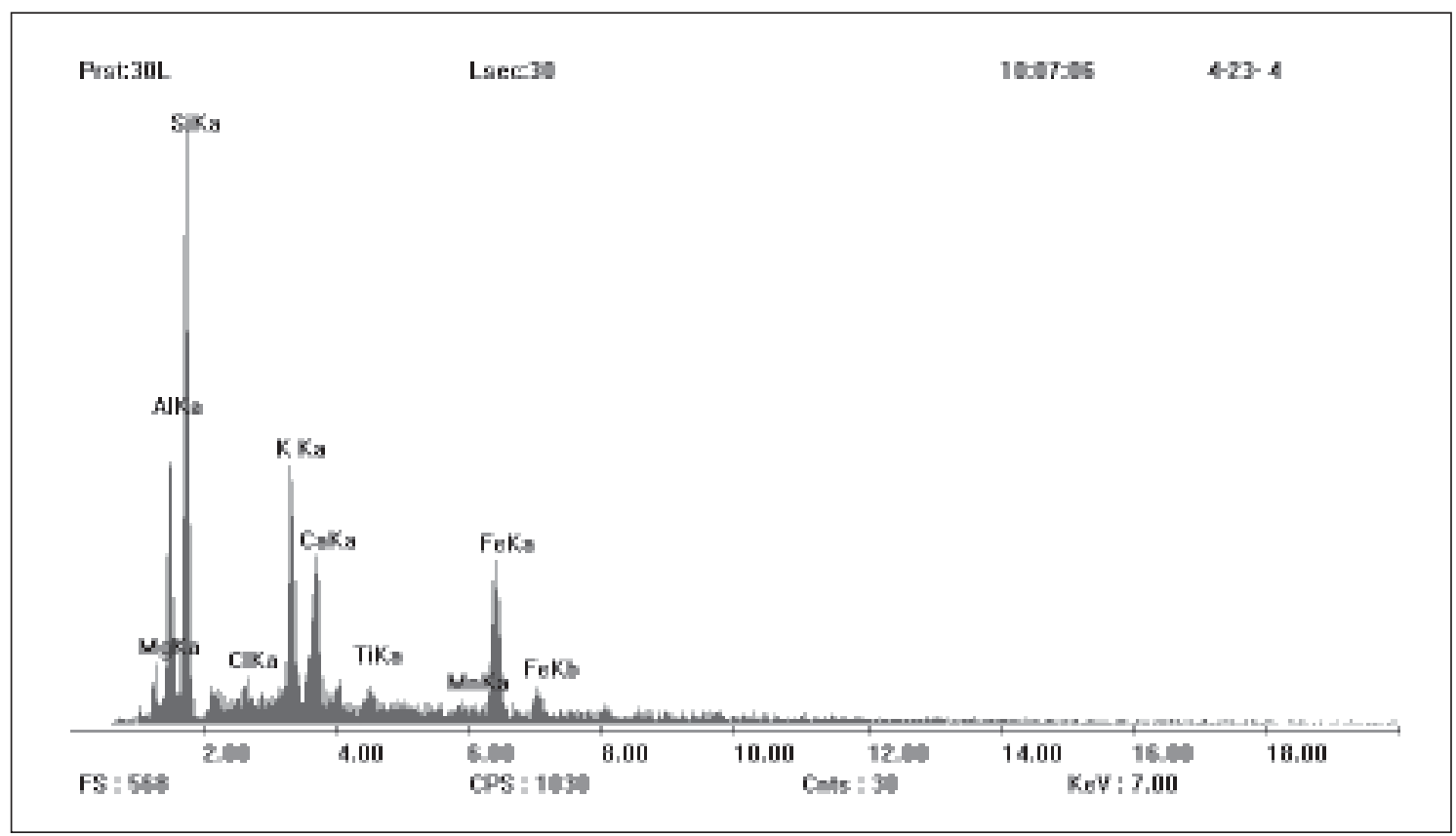

Gráfico 4. Fragmento TFS 334. Espectro 3.

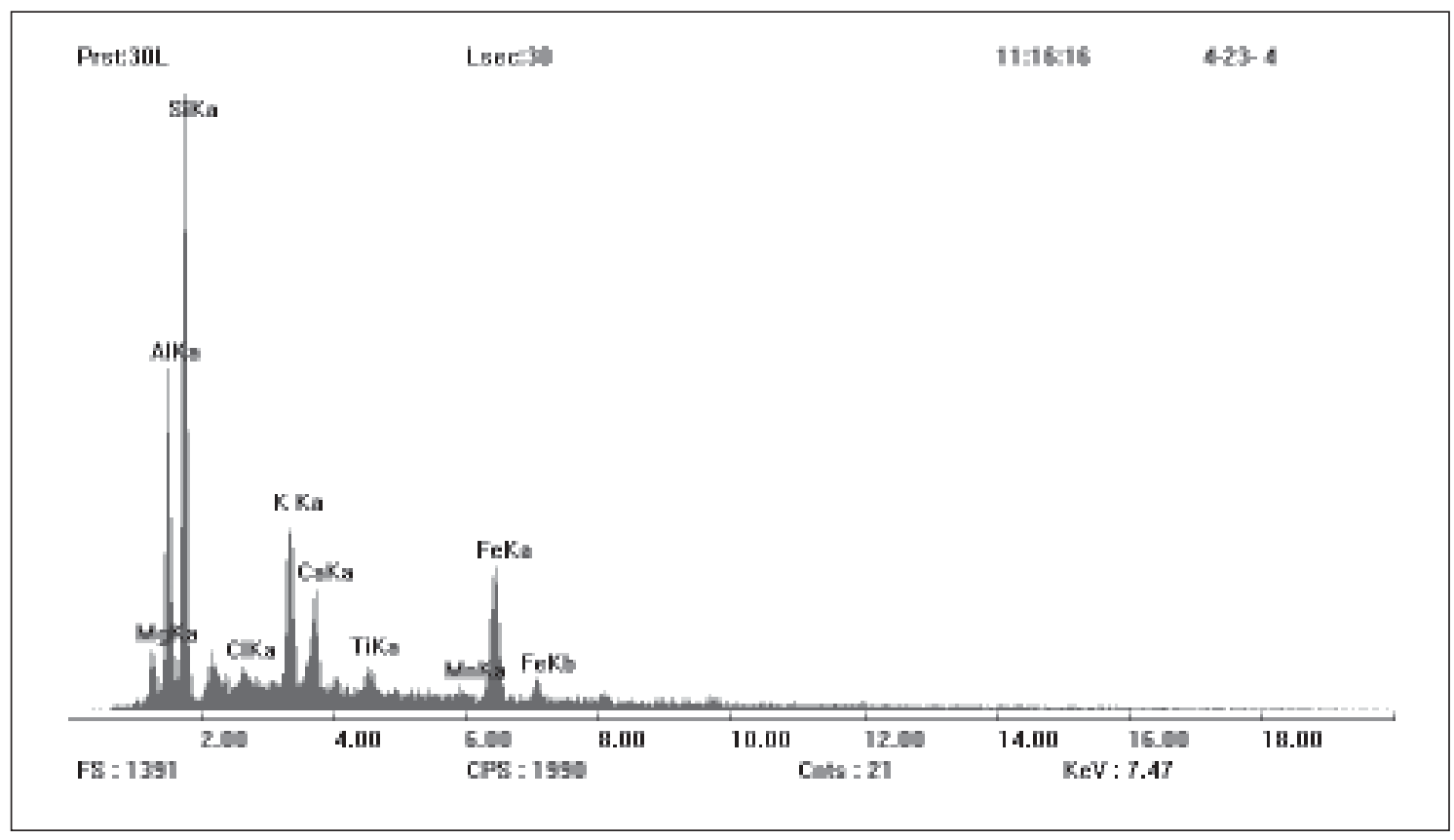

Gráfico 5. Fragmento TFS 334. Espectro 4.

El pigmento rojo tiene su fuente mineral en un coloide rico en hematita $\left(\alpha-\mathrm{Fe}_{2} \mathrm{O}_{3}\right)$ que es la principal fuente de óxidos de hierro $\left(\mathrm{FeO}_{2}\right)$ naturales. El $\mathrm{FeO}_{2}$ se vuelve rojo bajo atmósferas de cocción oxidantes. Del análisis del espectro del Grá- fico 3 correspondiente al pigmento rojo, surge que el titanio (Ti) está presente en porcentajes ínfimos, menores del $1 \%$, por lo que no se descarta la presencia de ilmenita $\left(\mathrm{Fe}^{+2} \mathrm{TiO}_{3}\right)$, un óxido de hierro con contenidos de Ti (ver Nota 9). 
El análisis del engobe de color marrón revela que se trata de una solución coloidal (mineral arcilloso) que presenta un alto contenido de hierro y potasio, además del aluminosilicato, con lo cual es una típica solución arcillosa diluida. Un análisis de difracción de rayos X preliminar sobre este engobe indica que se trataría del mineral arcilloso illita $-\left[\left(\mathrm{Al}_{2}, \mathrm{Fe}_{2}, \mathrm{Mg}_{2}, \mathrm{Mg}_{3}\right)\left(\mathrm{Si}_{4-x} \mathrm{Al}_{x}\right) \mathrm{O}_{10}(\mathrm{OH})_{2}\right] \mathrm{K}_{x}-$ (Faure 1998: 202-208), aunque faltan otros análisis adicionales para corroborar esta afirmación. El contenido de calcio observado en esta superficie (Figura 5b) se asigna a alteraciones postdepositacionales de carbonatos de calcio $\left(\mathrm{CaCO}_{3}\right)$ corroboradas por el análisis por microscopia binocular y petrología; la presencia de dolomita $(\mathrm{CaMg}$ $\left.\left(\mathrm{CaO}_{3}\right)_{2}\right)$ no es descartada y será corroborada en análisis posteriores (ver Nota 9).

Los resultados del microanálisis obtenidos para la superficie interna Negro Pulido -denominado "grafitado"- de este puco se presentan como típicos del análisis de un cuerpo cerámico, por lo que en este estudio no se puede discernir si se ha aplicado una fracción con contenido de grafito previamente a su pulido y bruñido.

\section{Discusión y conclusiones}

Este estudio preliminar de petrología cerámica y análisis composicional de las pinturas del estilo cerámico Aguada Portezuelo revela que la muestra de fragmentos analizada procedente de tres sitios arqueológicos del valle de Catamarca (Portezuelo, La Carrera y Tiro Federal Sur) presenta una composición mineralógica extremadamente homogénea, caracterizada principalmente por la presencia de inclusiones de cuarzo redondeadas (arenas cuarzosas típicas de ambientes fluviales), inclusiones de biotita y muscovita, combinadas en bajas proporciones con fragmentos de rocas ígneas (plutónicas) -granito-, feldespatos plagioclasa y algunos minerales máficos como anfíbol -hornblenda parda- y piroxenos. Esta composición homogénea puede ser tentativamente relacionada con la existencia de un centro de producción cerámica localizado en el valle de Catamarca para el Período Medio o de Integración Regional (Pérez Gollán 1994) produciendo este estilo cerámico en sus diferentes modalidades, aunque para corroborar definitivamente esta afirmación deben realizarse análisis adicionales de caracterización química multielemental.
Los resultados obtenidos en el estudio de petrología cerámica básicamente son comparables con aquellos obtenidos por Cremonte y colaboradores (2003: 10-12) para los materiales cerámicos del sitio Choya-68, confirmando la utilización de materias primas locales, principalmente arenas cuarzosas redondeadas, para la confección de esta alfarería. No obstante, algunas diferencias en la utilización de fragmentos de roca fueron observadas en nuestro estudio, como, por ejemplo, la utilización sólo de fragmentos de rocas ígneas plutónicas (granito) en contraste con la identificación de fragmentos de rocas metamórficas realizada por Cremonte y colaboradores (2003: 10). Por otro lado, respecto del análisis por EDAX realizado por estos autores, podemos mencionar que nosotros obtuvimos resultados generales muy similares para los pigmentos estudiados, identificando a las fuentes de los mismos como de origen mineral, a excepción del pigmento negro que en nuestra muestra estuvo caracterizado por la determinación de altas concentraciones de $\mathrm{Fe}(71.76 \%)$ y en menor cantidad por Mn (14.37\%) (ver Tabla 3). Esto contrasta con los resultados obtenidos por Cremonte y colaboradores (2003: 12, Tabla 1), donde el Mn presenta el porcentaje más alto (28.64\%) y en menor concentración el Fe (12.06\%), lo que se debe a que el Fe puede generar también el color negro (p.e., hematita) en las siguientes situaciones: 1) si es utilizado como tratamiento postcocción; 2) si no es sometido a un proceso de oxidación a altas temperaturas; 3) o bajo condiciones de cocción reductoras (Shepard 1936: 39). En nuestro caso es probable que se haya utilizado una combinación de minerales, dado que la presencia de Mn es importante en la muestra analizada.

Adicionalmente, pudimos observar que las investigaciones de petrología cerámica fueron exitosas en la determinación de diferentes etapas técnicas en el proceso de manufactura de estas vasijas, involucrando una compleja "cadena operativa" caracterizada por la manufactura de cerámica con engobes conformados por gran cantidad de biotita como inclusión mineral, de aproximadamente 0.35 a $0.60 \mathrm{~mm}$ de espesor, con una orientación diferencial de las inclusiones y cocción oxidante sobre pastas cuya cocción se realizó en atmósferas reductoras (ver Figuras $4 \mathrm{e}$ y $5 \mathrm{e}$ ).

Esto indicaría que se estaban realizando por lo menos dos etapas técnicas: 1) elaboración de la 
forma base geométrica de la vasija y cocción en atmósferas reductoras, y 2) aplicación de un engobe (coloide rico en biotitas y muscovitas) o baño de hasta $1 \mathrm{~mm}$ de espesor, y una segunda cocción para lograr su fijación en condiciones atmosféricas oxidantes. Esta segunda cocción probablemente haya sido de menor temperatura y más corta.

Lo anterior implica un alto grado de especialización artesanal en la elaboración de estas vasijas, y un conocimiento tecnológico importante sobre la utilización de diferentes tipos de pigmentos y su fijación a diferentes superficies. Esta idea está apoyada por el registro de una pieza en la colección de Edwin Petek (com. pers., 2002) que presenta el cuerpo y la base cocidas en atmósfera reductora y el resto de la vasija (cuello y borde) con cocción oxidante.

Con relación a las pinturas analizadas por MEBEDS, la cerámica Aguada Portezuelo del valle de Catamarca exhibe una gran variación en la tecnología y en los pigmentos utilizados en su decoración. Los cuatro colores usados en este tipo cerámico (rojo, negro, blanco y marrón), pueden ser obtenidos de formas variadas. Los pigmentos rojos y marrones tienen su origen en ocres naturales (óxidos de hierro), cuya fuente principal es la hematita, mezclados con coloides de aluminosilicatos que forman el vehículo del pigmento.

Estas pinturas son pigmentos mates, no vidriados, y deben adherirse a la superficie de la vasija y retener el color después del proceso de absorción y fijado. Los pigmentos son incorporados a un coloide (aluminosilicato - mineral arcilloso) el cual forma el vehículo del pigmento y debe reunir condiciones específicas para lograr su absorción en la superficie de la pasta. Los pigmentos negros, los cuales presentan altas concentracio- nes de hierro $(\mathrm{Fe})$ y en menor medida manganeso $(\mathrm{Mn})$, tienen su fuente inorgánica en minerales tales como la hematita $\left(\alpha-\mathrm{Fe}_{2} \mathrm{O}_{3}\right)$, pirolusita $\left(\mathrm{Mn}^{+4} \mathrm{O}_{2}\right)$ y psilomelano $\left(\mathrm{BaMn}^{+2}+\mathrm{Mn}_{8} \mathrm{O}_{16}(\mathrm{OH})_{4}\right)$, y los pigmentos rojos, con altas concentraciones relativas de hierro (Fe), en el mineral hematita ( $\alpha$ $\mathrm{Fe}_{2} \mathrm{O}_{3}$ ). Los mismos fueron adicionados a soluciones coloidales -minerales arcillosos, por ejemplo illita- previa preparación técnica.

Por último, debe mencionarse que las superficies internas de color negro analizadas en este estudio, usualmente denominadas "grafitadas" -debido a la utilización de "grafito" para su pulido o bruñido-, requieren otro tipo de análisis con técnicas analíticas sensibles a la presencia de estructuras orgánicas como por ejemplo FTIR (Espectroscopia Infrarroja con Transformada de Fourier) y Espectroscopia de Ramán.

Agradecimientos Un especial agradecimiento a los Dres. John Twilley, Warren E. Straszheim y Chris Salter por sus sugerencias con respecto a cuestiones técnicas sobre los análisis de materiales arqueológicos mediante la técnica analítica de MEB-EDS, especialmente aplicados a cerámicas arqueológicas. Al Dr. Christopher Carr, del Depto. de Antropología de la Universidad de Arizona y al Dr. Andrew Middletone, del British Museum, por haber colaborado con sus valiosos trabajos. A la SeCyT de la Universidad Nacional de Catamarca por los fondos y subsidios a los diferentes proyectos dirigidos por el Dr. N. Kristcautzky, dentro de los cuales se recolectaron los materiales analizados en este trabajo. Al equipo técnico de la Unidad de Materiales del Centro Atómico Constituyentes, Comisión Nacional de Energía Atómica, por su colaboración en los estudios analíticos por MEB-EDS, y al personal técnico de la Facultad de Química de la Universidad de San Luis por las imágenes tomadas con MEB.

\section{REFERENCIAS CITADAS}

BALDINI, M., J. CARBONARI, G. CIEZA, M. E. DE FEO, M. F. DEL CASTILLO, A. FIGINI, A. R. GONZALEZ, R. HUARTE y J. TOGO, 2002. Primer análisis de la cronología obtenida en el sitio Choya-68 (Depto. de Capayán, Provincia de Catamarca, Argentina). Estudios Atacameños 24: $71-82$
BARRACLOUGH, A., 1992. Quaternary sediment analysis: A deductive approach at A-Level. Teaching Geography 17: 15-18.

BARRIONUEVO, O., 1971. Investigaciones arqueológicas en Nana Huasi, Ancasti. Cuadernos de Antropología Catamarquẽ̃a 4: 1-15. 
CABRERA, A. y A. WILLINK, 1973. Biogeografía de América Latina. Serie de Biología. Monografía 13. Secretaría General de la Organización de los Estados Americanos, Washington, D. C.

CARR, C., 1990. Advances in ceramic radiography and analysis: Applications and potentials. Journal of Archaeological Science 17: 13-34.

CREMONTE, M. B., M. BALDINI e I. L. BOTTO, 2003. Pastas y colores. Un camino al conocimiento del estilo Portezuelo de Aguada. Intersecciones en Antropología 4: 3-16.

DE LA FUENTE, G. A., N. KRISTCAUTZKY, y G. TOSELLI, 2004. Pigmentos, engobes y alfareros: Una aproximación arqueométrica (SEM-EDS) al estudio tecnológico de pigmentos en cerámicas arqueológicas del Noroeste Argentino. El caso del tipo cerámico "Aguada Portezuelo" del valle de Catamarca. En Libro de Resúmenes del XV Congreso Nacional de Arqueología Argentina, Río Cuarto, 20-25 de septiembre de 2004, pp. 140. Universidad Nacional de Río Cuarto, Córdoba.

FAURE, G., 1998. Principles and applications of geochemistry. Segunda Edición. Prentice Hall, Inc., New Jersey.

FREESTONE, I. C., 1991. Extending ceramic petrology. En Recent developments in ceramic petrology, A. P. Middletone e I. C. Freestone (Eds.), pp. 399-410. British Museum Occasional Paper 81, Londres.

GONZALEZ, A. R., 1998. Arte precolombino. Cultura La Aguada. Arqueología y sus diseños. Filmediciones Valero, Buenos Aires.

GORDILLO, I., 1996-97. Una cuestión de tiempo. Shincal 6: $15-25$.

HABER, A., 1992. La Aguada en el valle de Catamarca. Detección y características de sitios en la cuenca ConetaMiraflores (Huillapima, Capayán, Catamarca, Argentina). Boletín del Museo Regional de Atacama 4: 71-83.

HABER, A., J. A. FERREYRA, M. G. GRANIZO, M. N. QUESADA y M. F. VIDELA, 1996. Construcción de categorías de paisaje en Capayán. Shincal 6: 83-100.

HARGRAVE, L. y W. SMITH, 1928. A method for determining the texture of pottery. American Antiquity (2) 1: 32-36

KRISTCAUTZKY, N. y J. TOGO, 1996. Prospección arqueológica en el Valle Central de Catamarca. Departamentos Valle Viejo, Capital, Fray Mamerto Esquiú, Paclín y Ambato. En Actas y Memorias del XI Congreso de Arqueología Argentina (13 parte), Revista del Museo de Historia Natural de San Rafael, T. XXV (1/4): 141-153.

KUSCH, M. F., 1991. Forma, diseño y figuración en la cerámica pintada y grabada de La Aguada. En El arte rupestre en la arqueología contemporánea, M. Podestá, M. I. Hernández-Llosas y S. Renard (Eds.), pp. 14-24. FECIC, Buenos Aires.
1996-97. Estructura y diseño en la cerámica Portezuelo. Shincal 6: 241-248.

KUSCH, M. F. e I. GORDILLO, 1997. Interacción y paisaje social en La Aguada. Los espacios del jaguar. Estudios Atacameños 14: 85-93.

KUSCH, M. F., M. HOFFMAN y C. ABAL, 1997. Variabilidad estilística en torno a la iconografía humano-felínica durante el Período Formativo (Catamarca y La Rioja). En Actas y Memorias del XI Congreso Nacional de Arqueología Argentina ( $4^{\circ}$ parte), Revista del Museo de Historia Natural de San Rafael T. XVI, (1/4): 183-202.

LAFONE QUEVEDO, S., 1892. Catálogo descriptivo e ilustrado de las huacas de Chañar Yaco. Revista del Museo de La Plata III: 35-62.

MATHEW, A. J., A. J. WOODS, y C. OLIVER., 1991. Spots before your eyes: New comparison charts for visual percentage estimation in archaeological material. En Recent developments in ceramic petrology, A. P. Middletone e I. C. Freestone (Eds.), pp. 211-263. British Museum Occasional Paper 81, Londres.

MIDDLETONE, A. P., I. C. FREESTONE, y M. N. LESSE, 1985. Textural analysis of ceramic thin sections: Evaluation of grain sampling procedures. Archaeometry 27 (1): 64-74.

PEREZ GOLLAN, J. A., 1991. La cultura de La Aguada vista desde el valle de Ambato. Publicaciones 46: 157-173.

-1994. El proceso de integración en el valle de Ambato: Complejidad social y sistemas simbólicos. Rumitacana 1 (1): 33-41.

RAVINES, R., 1989. Arqueología práctica. Editorial Los Pinos, Lima.

SERRANO, A., 1958. Manual de la cerámica indígena. Editorial Assandri, Córdoba.

SHEPARD, A. O., 1936. Technology of pecos pottery. En The pottery of pecos, vol. 2, A. V. Kidder y A. O. Shepard (Eds.), pp. 389-587. Papers of the Phillips Academy Southwestern Expedition 7. Yale University Press, New Haven.

SIMON, A., 1996. Pottery and pigments in Arizona: Salado Polychrome. Paper presented at Revelations beneath the surface: The science of art, Arizona State University, 1415 June, 1996. http://archaeology.asu.edu/vm/southwest/ salado/index.htm

PETEK, E., A. SESTO y V. MARENGO, 1972 Ms. Elementos de la cultura Aguada, comunes en área aledaña a la ciudad de Catamarca (Valles de Ambato y Catamarca).

WILSON, M. J. (Ed.), 1987. A Handbook of determinative methods in clay mineralogy. Blackie, Glasgow y Londres.

WOODS, A., 1984-85. An introductory note on the use of tangential thin-sections for distinguishing between wheelthrown and coil-ring-built vessels. Bulletin of the Experimental Firing Group 3: 100-114. 


\section{Anexo 1}

Fragmento TFS 334 (sitio Tiro Federal Sur)

Pasta: Constituida principalmente por inclusiones de cuarzo monocristalino $(52 \%)$ y biotita $(36 \%)$ de granulometría media y fina/media, respectivamente, complementada por fragmentos de roca ígnea plutónica $(6.4 \%)$ con texturas graníticas de granulometría media, homogéneamente distribuidas en la sección delgada. Los cuarzos presentan un grado de angularidad medio/bajo, son mayoritariamente cristales automorfos y algunos cristales están fracturados. También se observaron algunas inclusiones de cuarzo policristalino. Las inclusiones de biotita presentan sus formas típicas (laminillas) y tienen una distribución homogénea en la sección, siendo algunas de ellas de gran tamaño. Los fragmentos de granitos poseen un grado de angularidad medio/bajo y están constituidos por cuarzo, biotita, muscovita, y a veces combinados con la presencia de feldespatos plagioclasa alterados y anfíbol. Adicionalmente se observaron inclusiones aisladas de feldespatos plagioclasa (5.7\%) subangulosos, algunas de las cuales presentan alteraciones a sericita. La pasta presenta una orientación preferencial de las inclusiones, con una proporción del $20 \%$ y una buena distribución de los diferentes tamaños de antiplástico. El rango de tamaño más representado es el fino 3-4 (escala $\varphi$ ). El fragmento pertenece a la zona media del cuerpo de un puco Aguada Portezuelo del tipo Negro (10YR 3/1) y Rojo (5YR 4/4) sobre Ante (7.5YR 5/4) en su superficie externa y Negro Pulido (4/N) - grafitado- en su superficie interna (ver Figuras $2 \mathrm{~d}$ y $5 \mathrm{~b}$ ). El corte transversal mostrado en la Figura $5 \mathrm{~b}$ presenta los siguientes colores: $3 / \mathrm{N}$ superficie interna, 4/N sector medio del corte y 7.5YR 5/4 engobe superficie externa.

Matriz: Micácea (biotita) de granulometría ultra fina. No se observaron cambios fuertes en la coloración debida al proceso de cocción, ni ningún núcleo aparente. En el borde externo se observó la presencia de un engobe con cambio en la coloración de marrón suave amarillento / marón amarillento fuerte (engobe). La matriz es anisotrópica (ópticamente activa) y su composición al fondo es micácea (biotítica) homogénea de granulometría ultra fina.

Cavidades: De forma subcircular y elongadas con distribución uniforme, orientadas de manera paralela al eje longitudinal de la sección delgada. Oscilan en tamaño entre $0.1 \mathrm{~mm}$ y $0.4 \mathrm{~mm}$.

Observaciones generales: 1) Todas las inclusiones observadas en la sección presentan un grado de angularidad media/baja; 2) Existe engobe en el borde externo, con cocción oxidante, caracterizado por la gran cantidad de inclusiones de biotita orientadas a lo largo del eje longitudinal de la sección y con un espesor de aproximadamente $0.35 \mathrm{~mm}$; 3) Se observó bajo nicoles cruzados en XPL una unión claramente visible entre dos rodetes adicionados durante la manufactura de la vasija; esta unión está caracterizada por presentar una orientación preferencial de las inclusiones minerales de biotita y por fuertes cambios en la birrefringencia del material arcilloso en la zona de contacto.

El Gráfico 6 muestra la distribución de los diferentes tipos de antiplástico identificados por petrología cerámica en función de los rangos de tamaño presentes. Obsérvese que solamente están representados en el fragmento analizado los rangos de tamaño 3-4 y 2, con mayor cantidad de inclusiones en el rango 3-4 (escala $\varphi$ ) y los dos rangos presentes para todas las inclusiones analizadas. Este fragmento presenta una distribución bimodal especialmente para los cuarzos y la biotita pudiéndose inferir que las inclusiones correspondientes al rango 2 han sido agregadas intencionalmente a la pasta como antiplástico artificial.

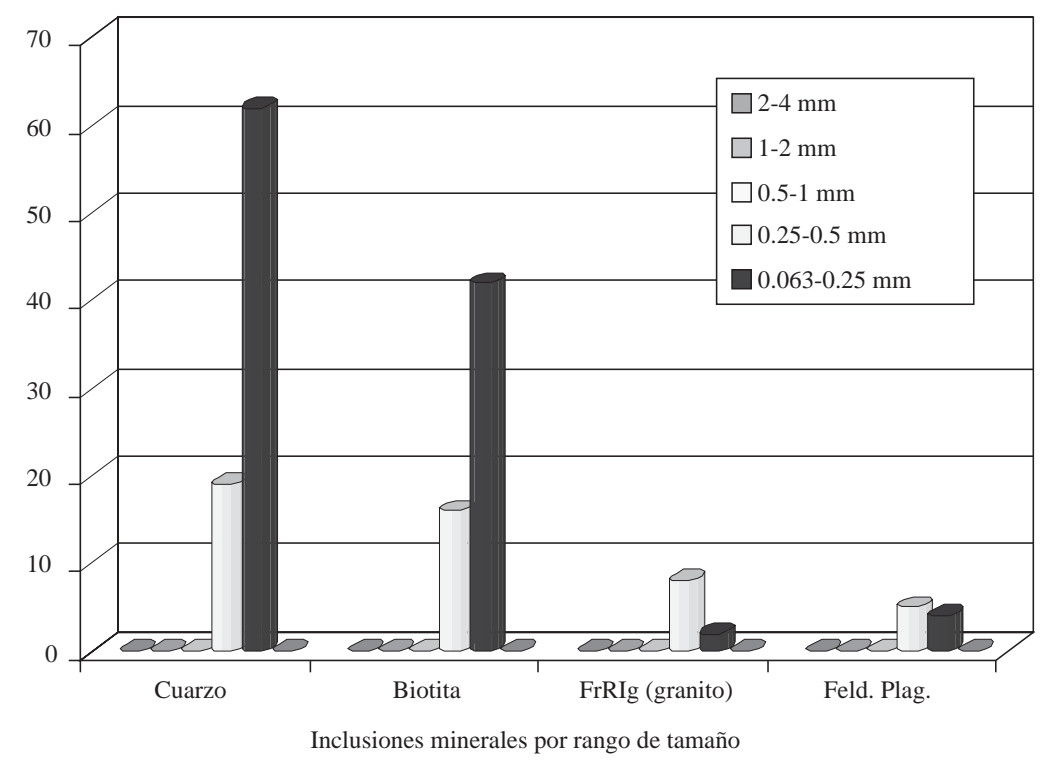

Gráfico 6. Distribución de inclusiones minerales y fragmentos de roca en fragmentos TFS 334. 